\title{
Two port laparoscopic trachelectomy without the use of ureteral stents
}

\author{
(D) Greg J. Marchand 1 , (D) Sienna Anderson 1 , (D) Stacy Ruther ${ }^{1}$, (D) Sophia Hopewell1, (D) Giovanna Brazil1, \\ (D) Katelyn Sainz ${ }^{1,2}$, (D) Hannah Wolf ${ }^{1}$, (D) Alexa King ${ }^{1}$, (D) Jannelle Vallejo ${ }^{1,2}$, (DD Kelly Ware ${ }^{1,3}$, \\ (D) Kaitlynne Cieminski1 ${ }^{1}$, (D) Anthony Galitsky1, (D) Ali Azadi1 \\ 1The Marchand Institute for Minimally Invasive Surgery, Mesa, AZ, United States of America \\ 2Washington University of Health and Science, San Pedro, Belize \\ 3International University of Health Sciences, Basseterre, St. Kitts
}

\section{Abstract}

Trachelectomy is a notoriously difficult laparoscopic procedure, often because of remaining scar tissue from a prior supracervical hysterectomy, as well as the necessity to clear vital organs, including the bladder and the rectum, out of the plane of dissection in order to remove the cervix. Many authors have suggested techniques involving ureteral stents to minimize the chance of ureteral injury. Our institute presents this two-port laparoscopic technique without the use of stents, which we believe safely accomplishes the trachelectomy through very minimally invasive means.

Keywords: Trachelectomy, laparoscopy, single port, two port, robotic

Received: 10 March, 2020 Accepted: 27 April, 2020

\section{Introduction}

Trachelectomy is a notoriously difficult laparoscopic procedure (1). The reasons for this include remaining scar tissue from a prior supracervical hysterectomy, as well as the necessity to clear vital organs, including the bladder and the rectum out of the plane of dissection in order to remove the cervix $(2,3)$. Based on our review of the literature, many authors have discussed the use of novel techniques $(4,5)$, ureteral stents $(6,7)$, and uterine manipulators (5) for the purpose of performing trachelectomy (8). In this video we present our technique for laparoscopic, two-port trachelectomy, using a novel approach of vaginal tension on the cervix to complete the colpotomy.

\section{Objective}

To demonstrate a technique to perform a laparoscopic trachelectomy in the safest, most minimally invasive, cost effective way possible, without the use of ureteral stents (Video 1). We designed a surgical technique including several novel aspects. First, we began dissection on the cervical stump with a linear horizontal incision to maximize the distance from the bladder and rectum (Figure 1). Next, we used a technique of maintaining pressure against the vaginal cuff, deep within the abdomen, to move the ureters laterally, thus eliminating the need for ureteral stents. We overcame the obvious problem of keeping the cervix planted against the manipulator by the novel usage of a laparoscopic tenaculum, used to hold the cervix from the vaginal approach through the manipulator (Figure 2). Thus we were able to complete the circumferential colpotomy (Figure 3 ) with the cervix firmly held against the internal ring of the manipulator at all times.

This manuscript has been reviewed by the Institutional IRB Board at Marchand Institute and was found to be exempt from IRB review (July 2018).

Address for Correspondence: Greg Marchand

e.mail: gm@marchandinstitute.org ORCID: orcid.org/0000-0003-4724-9148

( $C$ Copyright 2021 by the Turkish-German Gynecological Education and Research Foundation - Available online at www.jtgga.org

Journal of the Turkish-German Gynecological Association published by Galenos Publishing House.

DOI: 10.4274/jtgga.galenos.2020.2020.0027 


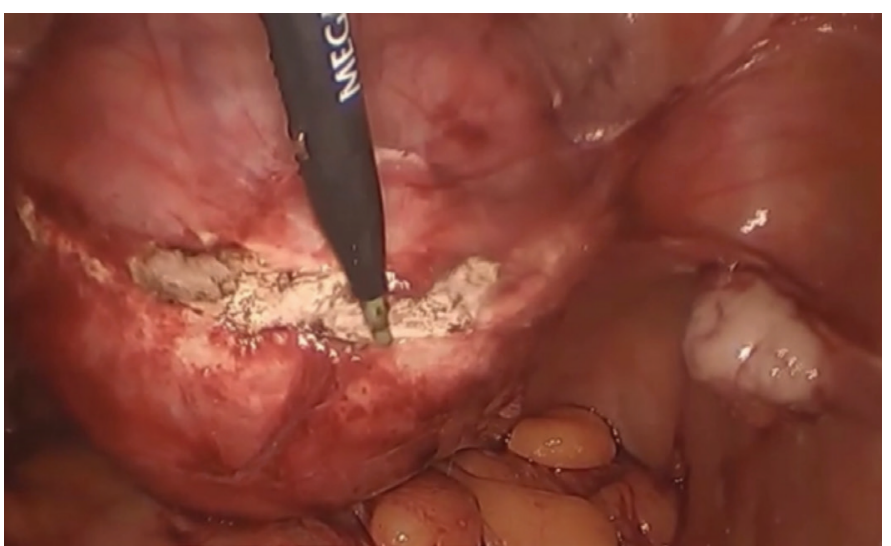

Figure 1. Initial dissection into the cervical stump is started in a linear pattern in order to maximize the distance from both the bladder and the rectum

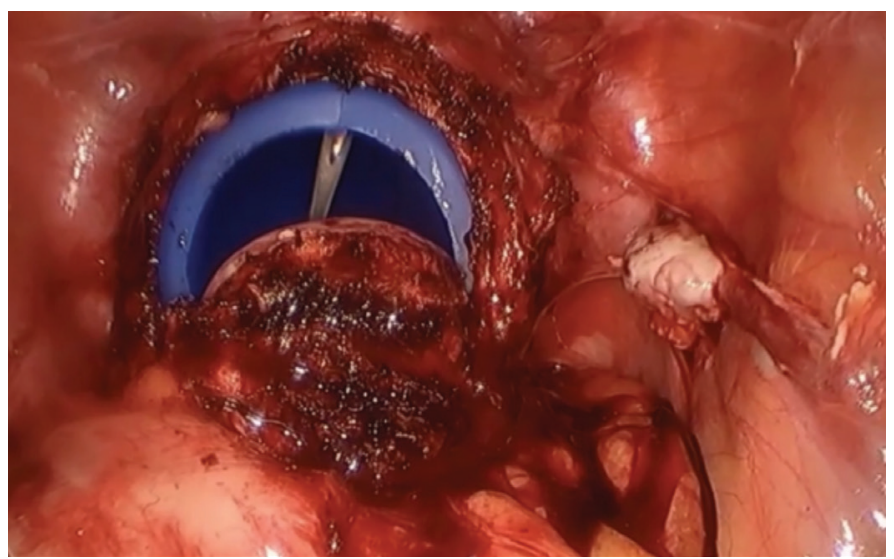

Figure 2. A $5 \mathrm{~mm}$ laparoscopic, sharp-tooth tenaculum is inserted vaginally in order to grasp the cervix and hold tension against the manipulator. This allows the manipulator to be pushed cephalad while completing the colpotomy. The resulting force pushed the ureters laterally, minimizing the risk of ureteral injury

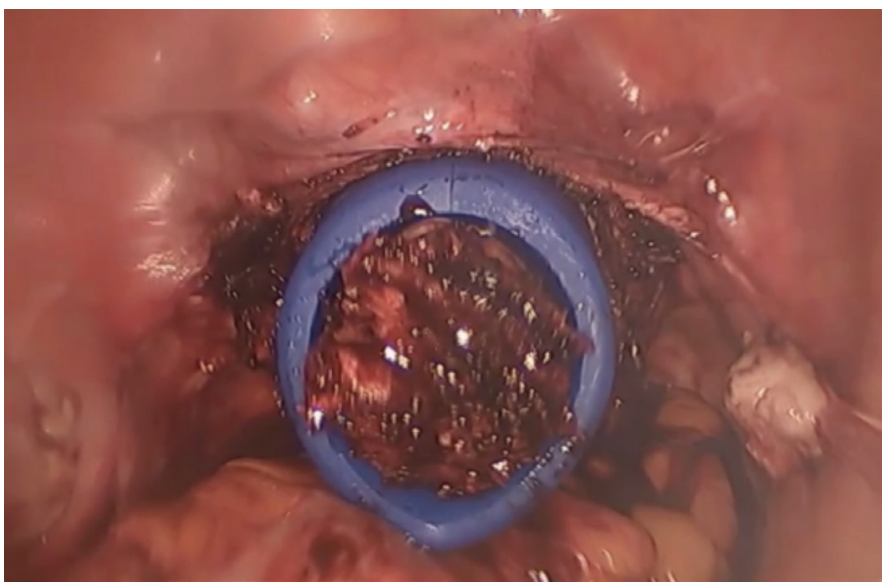

Figure 3. The colpotomy was completed and the cervix is free within the manipulator

\section{Design}

A narrated video demonstration of the surgical procedure (Canadian Task Force Classification III).

\section{Setting}

The setting was a suburban hospital in the United States.

\section{Interventions}

The patient was an obese, 46-year-old female with pain in the area of the cervix and vaginal bleeding 10 years after open supra-cervical hysterectomy. Two-port laparoscopic trachelectomy without ureteral stents was performed. Our novel technique was successful in completing the procedure without complications. We have explained the technique and instrumentation in this video, for reproducibility. The patient was discharged 26 hours after surgery and her recovery was uneventful.

\section{Conclusion}

This technique is a feasible, reproducible procedure for laparoscopic trachelectomy. Novel aspects of this technique may effectively eliminate the need for pre-operative ureteral stents in some cases.

Acknowledgement: The Marchand Institute for Minimally Invasive Surgery would like to acknowledge the efforts of all of the students, researchers, residents and fellows at the institute who put their time and effort into these projects without compensation, only for the betterment of women's health. We firmly assure them that the future of medicine belongs to them.

Video 1. Fully narrated video demonstration of our described technique of two port laparoscopic trachelectomy without the need for ureteral stents

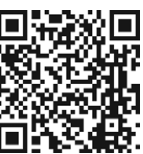

https://www.doi.org/10.4274/jtgga.galenos.2020.2020.0027.video1

Commitment to Diversity: The Marchand Institute remains committed to diversity and tolerance in its research, and actively maintains a workplace free of racism and sexism. Greater than half of the authors for this study are female and many represent diverse backgrounds and under-represented ethnic groups.

Informed Consent: Patient gave written consent for usage of video prior to and after procedure. 
Conflict of Interest: No conflict of interest was declared by the authors.

Financial Disclosure: The authors declared that this study received no financial support.

\section{References}

1. Parkar RB, Hassan MA, Otieno D, Baraza R. Laparoscopic trachelectomy for cervical stump 'carcinoma in situ'. J Gynecol Endosc Surg 2011; 2: 58-60.

2. Sheth SS. Vaginal excision of cervical stump. J Obstet Gynaecol 2000; 20: 523-4.

3. Pasley WW. Trachelectomy: A review of fifty-five cases. Am J Obstet Gynecol 1988; 159: 728-32.
4. Kaldawy A, Ostrovsky L, Segev Y, Lavie O. Laparoscopic cerclage during radical trachelectomy-a novel technique: a case report and review of the literature. J Gynecol Surg 2020; 36: 136-40.

5. Kho RM, Akl MN, Cornella JL, Magtibay PM, Wechter ME, Magrina JF. ncidence and characteristics of patients with vaginal cuff dehiscence after robotic procedures. Obstet Gynecol 2009; 114: 231-5.

6. Tsubamoto H, Kanazawa R, Inoue K, Ito Y, Komori S, Maeda H, et al. Fertility-sparing management for bulky cervical cancer using neoadjuvant transuterine arterial chemotherapy followed by vaginal trachelectomy. Int J Gynecol Cancer 2012; 22: 1057-62.

7. Demir RH, Marchand GJ. Improved vaginal manipulator for laparoscopic sacrocolpopexy. J Minim Invasive Gynecol 2012; 19: S181.

8. Nezhat $\mathrm{CH}$, Rogers JD. Robot-assisted laparoscopic trachelectomy after supracervical hysterectomy. Fertil Steril 2008; 90: 850.e1-3. 